RUNNING HEAD: Errors in drawing

\title{
The genesis of errors in drawing
}

\section{Rebecca Chamberlain and Johan Wagemans ${ }^{1}$}

${ }^{1}$ Laboratory of Experimental Psychology, KU Leuven

Correspondence concerning this article should be addressed to Rebecca Chamberlain, Laboratory of Experimental Psychology, KU Leuven, Tiensestraat 102, Leuven 3000, Belgium. E-mail:

rebecca.chamberlain@kuleuven.be 
Errors in drawing

\begin{abstract}
The difficulty adults find in drawing objects or scenes from real life is puzzling, assuming that there are few gross individual differences in the phenomenology of visual scenes and in fine motor control in the neurologically healthy population. A review of research concerning the perceptual, motoric and memorial correlates of drawing ability was conducted in order to understand why most adults err when trying to produce faithful representations of objects and scenes. The findings reveal that accurate perception of the subject and of the drawing is at the heart of drawing proficiency, although not to the extent that drawing skill elicits fundamental changes in visual perception. Instead, the decisive role of representational decisions reveals the importance of appropriate segmentation of the visual scene and of the influence of pictorial schemas. This leads to the conclusion that domain-specific, flexible, top-down control of visual attention plays a critical role in development of skill in visual art and may also be a window into creative thinking.
\end{abstract}


Errors in drawing

\section{Introduction}

The difficulty adults find in drawing objects or scenes from real life is puzzling. Intuitively, individuals should be able to commit their perceptual experience to a graphic representation, assuming that there are few gross individual differences in the phenomenology of visual scenes and in fine motor control in the neurologically healthy population. However, the majority of adults are rarely able to put down a passable likeness of their visual experience onto paper. Drawing behaviours are commonly observed in children and are often regarded as indicators of emotional and cognitive development, but very few individuals go on to draw regularly in adulthood. Many visual artists find that drawing is an important technical and exploratory tool. The development of high-level drawing skill has been found to be underpinned by practice and a flexible approach to drawing techniques (Chamberlain et al., 2015). As a result, artists are often searching for techniques that improve their drawing skills and reduce the number of errors they make.

\section{The Psychological Study of Drawing}

The use of drawing as a vehicle for the investigation of perceptual processing, expertise and manifestations of creativity by cognitive scientists and neuroscientists has proliferated in the last two decades. Some researchers have used drawing as a window into visual perception, emotion, development and cognition (Cavanagh, 2005; Jolley, O’Kelly, Barlow, \& Jarrold, 2013; Karmiloff-Smith, 1990;

Tversky, 1990), while others are interested in the artistic process itself (Cohen \& Bennett, 1997; Edwards, 1989; Kozbelt, 2001; Mitchell, Ropar, Ackroyd, \& Rajendran, 2005).

In a paper entitled 'Why can't most people draw what they see?' Cohen and Bennett (1997) addressed the title question of the article by proposing four psychological sources for drawing errors:

1. Misperception of the object

2. Misperception of the drawing 
Errors in drawing

3. Motor skills

4. Representational decisions

The authors constructed a series of drawing experiments to isolate these aspects of the drawing process. The various conditions participants underwent included: tracing a photograph, drawing a photograph, drawing a tracing, and tracing a tracing. By comparing performance on these conditions the authors intended to determine which process best predicted the generation of drawing errors. They concluded that misperception of the object was at the heart of drawing inaccuracy due to the fact that the largest drawing errors were made in the drawing conditions relative to the tracing conditions. In addition, they acknowledged smaller contributions by poor representational decisions and misperception of the drawing and a very minor contribution by fine motor skills. Despite some methodological limitations, this early study provided the impetus for more controlled investigations into the basis of drawing errors and is a useful tool for decomposing the different aspects of cognitive and perceptual function underpinning drawing ability.

\section{Aims}

This review will follow-up Cohen and Bennett's (1997) paper by synthesising lines of psychological and neuroscientific evidence on drawing that have emerged since its publication. In addition, the role of visual memory performance in drawing will be investigated. This aspect of the drawing process was conspicuously lacking in Cohen and Bennett's analysis, given the commonly held conception that drawing always involves some reliance upon visual memory systems in the transfer from subject to paper. Individual differences in visual memory fidelity and duration could account for the differences found between the tracing and traditional drawing condition in Cohen and Bennett's study and therefore it is worthwhile assessing relative contributions of visual perception, encoding and retention in the drawing process. The overarching aims of the review are to enable drawing teachers and practitioners to understand the best channels through which to improve drawing ability, to provide research avenues for 
Errors in drawing

psychologists and neuroscientists in the visual arts to focus on in the future, and to clarify the critical role drawing plays in artistic practice.

\section{Defining drawing accuracy}

In the majority of studies presented in this review drawing accuracy is defined by independent observers' ratings of accuracy, which commonly show between-rater reliability estimates of around $a=.80-.90$. In other studies, drawings are compared directly with photographic stimuli. It has been found that subjective drawing accuracy rating correlates significantly with shape analyses of accuracy (Chamberlain et al., 2014). However, both art historians and psychologists of the arts have highlighted that drawing accuracy does not map directly onto photographic accuracy. For example, in a series of studies comparing photographs of scenes in paintings by Paul Cezanne and drawings by art students, Pepperell and Haertel (2014) found that the region of the scene corresponding to the central visual field was enlarged in paintings and drawings compared with a photograph, while the peripheral region was compressed. In a complementary study, Baldwin et al. (2014) compared artists' depictions of space to a number of geometrical perspective projections and reported that the artists' renderings matched the perceptual experience of observers better than geometrical projections. On the basis of this evidence, studies reporting shape analysis as a proxy for drawing accuracy should be treated with caution, bearing in mind artists frequently introduce systematic distortions into their drawings.

\section{Misperception of the object and the drawing}

Cohen and Bennett (1997) concluded that misperception of the artists' drawing did not explain a large amount of variance in drawing errors in their original study. This was due to the fact that there was no correlation between how much an individual overestimated the accuracy of their drawing and their actual drawing ability. However, Perdreau and Cavanagh (2015) recently found that individuals who could identify changes in both their drawing and the to-be-drawn object subsequently produced better drawings. This suggests that misperception of one's drawing plays a greater role than Cohen and Bennett (1997) 
Errors in drawing

initially concluded and is worthy of further investigation. The majority of researchers in this domain conflate misperception of the drawing and the to-be-drawn object by testing participants on domaingeneral perceptual tasks which are then correlated with performance on drawing tasks (which invariably demand accurate perception of both the subject and the drawing). Given the scarcity of findings that speak to the distinction between perception of the subject and the drawing, the remaining discussion applies to perception of both stimuli.

When addressing how misperception accounts for drawing errors it is important to highlight the distinction between two kinds of perceptual phenomena: illusions and delusions. Illusions are defined as failures of perception, while delusions are framed as failures of conception (Gregory, 2003). This distinction was introduced by Cohen and Bennett's (1997) and is a useful way of carving up the evidence in this field. Whilst at first glance the distinction between illusions and delusions may be clear, it is probably more appropriate to consider illusions and delusions on a continuum, ranging from conception to perception (Figure 1). More controversial examples in this field lie in the middle of this spectrum and include allocation of visual attention and the impact of stored canonical representations. In this review these phenomena are labelled as delusions rather than illusions, as they represent top-down influences on visual perception, often driven by conceptual knowledge about pictorial representation and object properties. However, it is clear that the categorisation of these phenomena is a continuing source of debate (see Firestone \& Scholl, in press). 


\section{Illusions}

\section{Delusions}

\section{Visual illusions \\ Amodal completion \\ Gestalt grouping \\ Perceptual constancies \\ - Color constancy \\ - Shape constancy \\ - Size constancy}

Visual attention

- Local processing

- Global processing

Perceptual representations

- Canonical percepts

- Long term visual memory
Conceptual representations

- Facial proportion knowledge

- Anatomical knowledge

- Categorical attribute relations

Figure 1. The illusion-delusion continuum and associated visual phenomena relevant to the study of drawing.

Illusions. Cohen and Bennett (1997) argued that both artists and non-artists are affected to the same extent by visual illusions, which they define as perceptual effects that cannot be corrected by a force of will. Much of the research concerning the impact of illusory percepts on drawing errors involves studying individual differences in perceptual constancy. Perceptual constancies are classified as illusions in this context as they rely on cues from the environment that imply the distal properties of objects functioning within the perceptual module. In the case of size and shape constancy, which have been thoroughly studied in this field, these cues are perspectival depth cues. It has been proposed that expert draftsmen are able to override perceptual constancies in order to access a more 'veridical' representation. This relates to the theory of John Ruskin, the famous art critic, who argued that artistic skill is acquired through 'innocence of the eye'(Ruskin, 1856).

The whole technical power of painting depends on our recovery of what may be called the innocence of the eye; that is to say, of a sort of childish perception of these flat 
Errors in drawing

stains of colour, merely as such, without consciousness of what they might signify, - as

a blind man would see them if suddenly gifted with sight. (p. 27)

An example of this can be seen in the work of impressionist painter Pierre-Auguste Renoir, in which the colour of dappled sunlight on the subjects of the painting in Figure 2 takes on a multiplicity of shades, when the visual system would normally account for variation in lighting through colour constancy mechanisms. The impressionist painter Claude Monet also expressed the concept of the innocent eye when he said, 'When you go out to paint try to forget what object you have before you - a tree, a house, a field or whatever. Merely think, here is a little square of blue, here an oblong of pink, here a streak of yellow, and paint it just as it looks to you, the exact colour and shape, until it emerges as your own naive impression of the scene before you' (Bomford, 1990, p. 83).

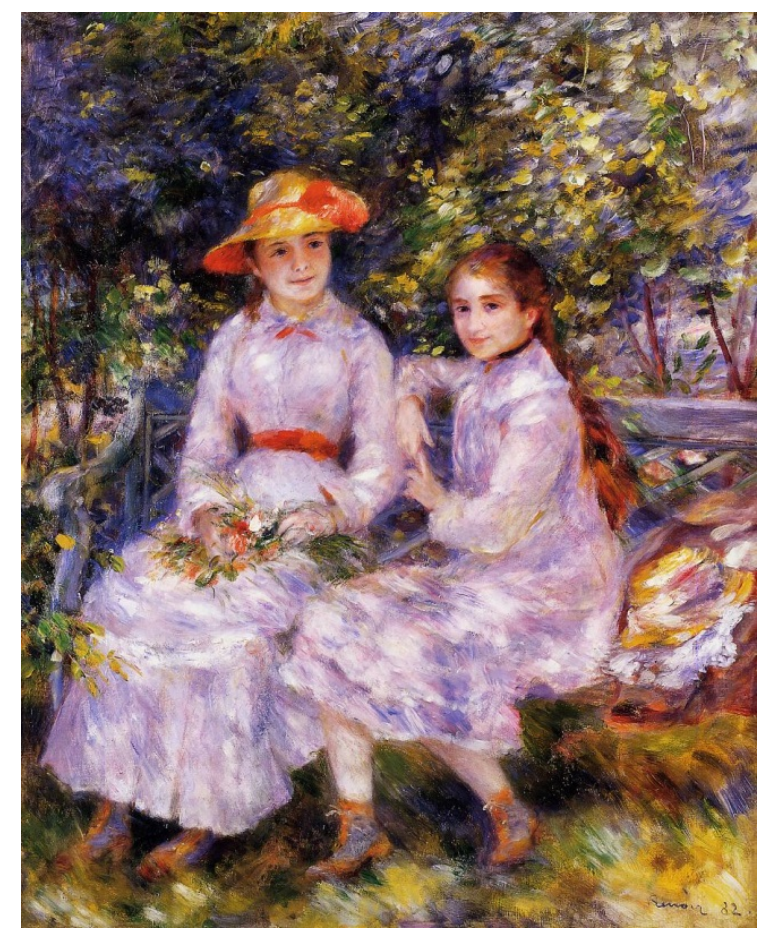

Figure 2. The daughters of Paul Durand Ruel (Pierre-Auguste Renoir, 1882).

Despite strong art theoretical perspectives of the importance of the innocent eye, empirical evidence for a correlation between the strength of perceptual constancy mechanisms and artistic ability is 
Errors in drawing

mixed. In an early study following Thouless'(1932) work on phenomenal regression in visual artists, Taylor and Mitchell (1997) found that both student artists and non-artists exaggerated the circularity of an ellipse when attempting to match it on a computer screen; there was no significant difference in shape constancy between the two groups. From this point of departure, a number of researchers investigated the link between artistic ability and perceptual constancy. Mitchell et al. (2005) compared non-artists' errors when drawing a simple parallelogram vs. when drawing the same parallelogram with lines added to make it look like a table (the Shepard Illusion; Figure 3). They found that participants made greater drawing errors when the parallelogram had added perspectival cues. Furthermore, the degree of perceptual error made in a size estimation task correlated with the degree to which errors were made when drawing the figures, suggesting that perspectival cues leading to the engagement of shape constancy mechanisms were responsible for drawing errors in the task.
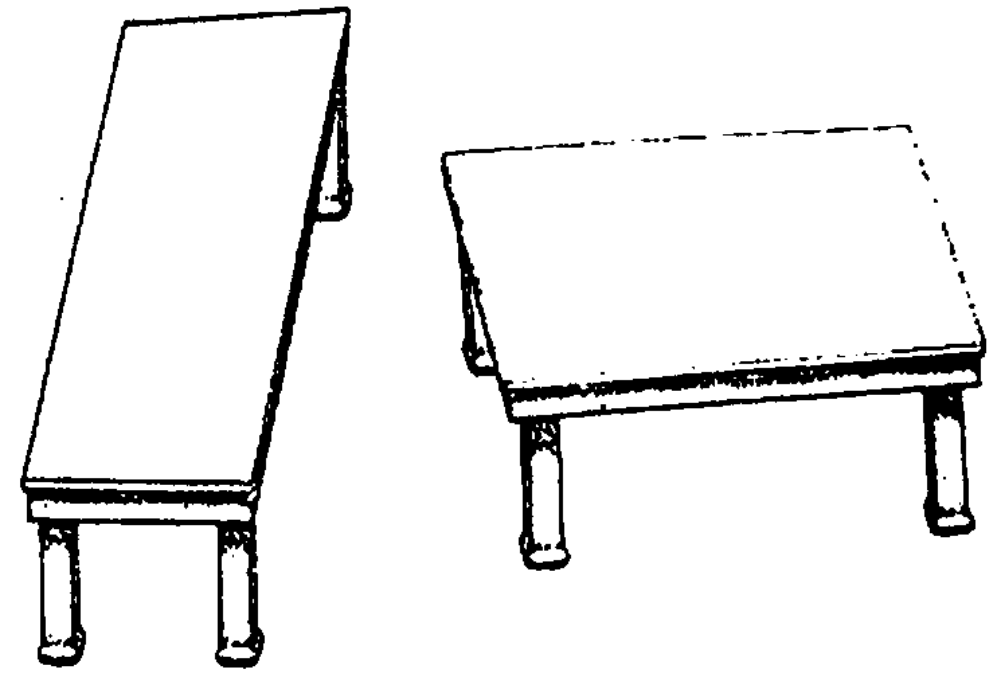

Figure 3. The Shepard Illusion from Mitchell et al. (2005).

Cohen and Jones (2008) measured individual differences in shape constancy by asking participants to match the shape of a window in perspective to a $2 \mathrm{D}$ outline. The sample as a whole showed skewed perception of the window shapes, but the degree of shape constancy was negatively 
Errors in drawing

related to accuracy in an observational drawing task, suggesting that the better draftsmen showed attenuated shape constancy. However, follow-up studies using this particular paradigm have failed to find support for Cohen and Jones' (2008) finding. McManus, Loo, Chamberlain, Riley and Brunswick (2011) were unable to replicate Cohen and Jones' (2008) study with computer-generated stimuli with a higher degree of control (Figure 4). Similarly, Ostrofsky, Kozbelt and Seidel (2012) found no evidence for a relationship between shape constancy and drawing ability in a similar task. However, the authors did find that the degree of size constancy related to drawing accuracy, providing some support for the notion that reduced influence of contextual illusions on target features ground drawing ability. In a comprehensive study, Perdreau and Cavanagh (2011) compared constancy mechanisms in artists and non-artists and found no evidence for group differences in lightness and size constancy or the ability to a-modally complete simple shapes.
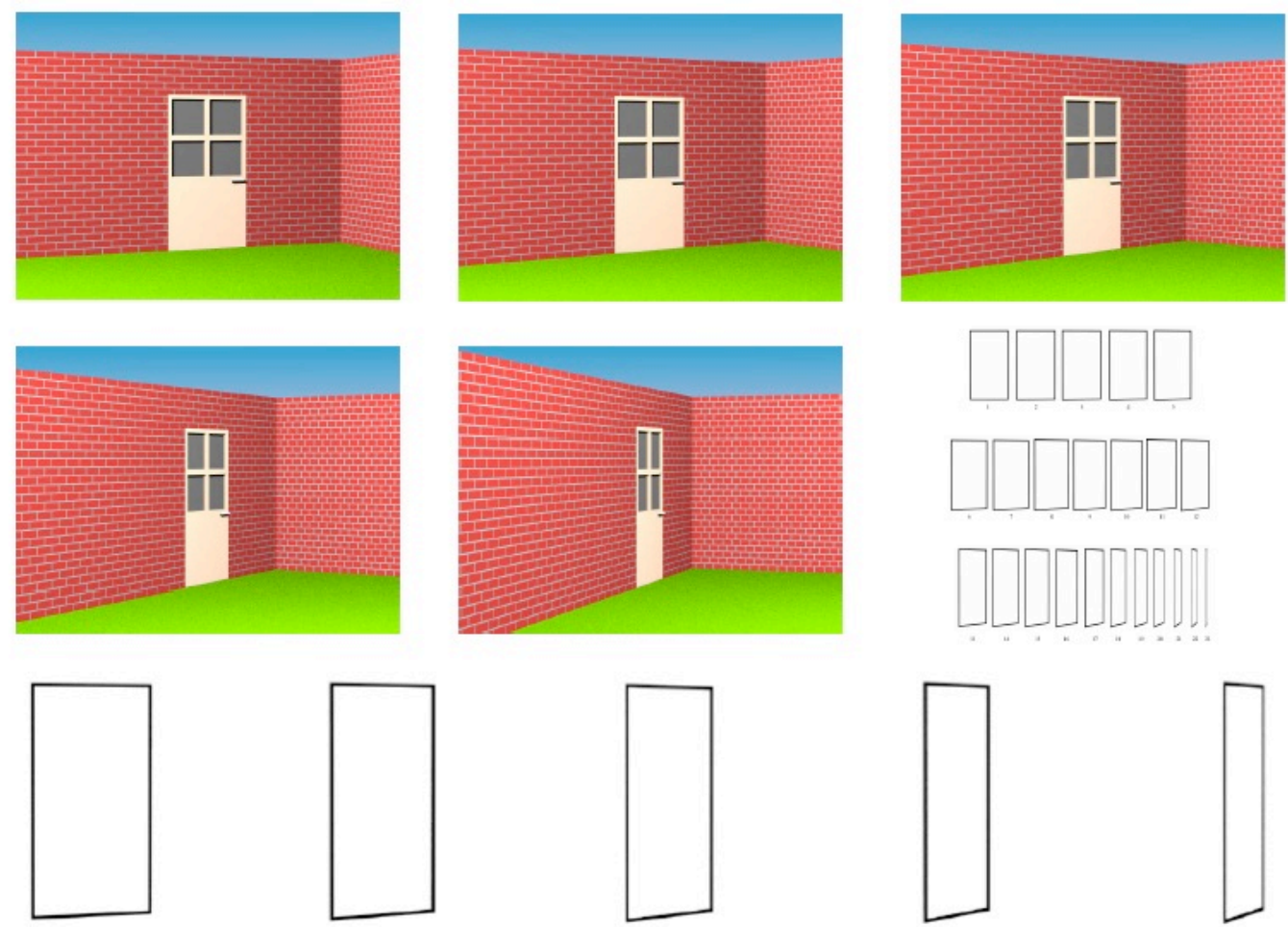

Figure 4. The shape constancy task used in McManus et al. (2011) with parallelograms embedded in a computer-generated context (top two rows) or presented as simple shapes (bottom row). 
Errors in drawing

The study of angular illusions is related to shape constancy, as a proportion of angle illusions are thought to have their foundations in shape constancy mechanisms (Hammad, Kennedy, Juricevic, \& Rajani, 2008). In a systematic study of angular illusions, which either did or did not rely on the processing of 3D depth cues (i.e. were reliant or not reliant on shape constancy mechanisms), Ostrofsky, Kozbelt and Jones (2015) found that there was a correlation between perceptual reproduction of angles embedded in triangles (no 3D cues) and quadrilaterals (3D cues) and errors made when drawing the same angles. Similarly, Chamberlain, McManus, Riley, Rankin and Brunswick (2014) found that context-free angular reproduction accuracy correlated with the drawing accuracy. Drawing experience correlated with the accurate perception of those angles embedded in simple 2D geometric figures or within a complex still life (Carson \& Allard, 2013; Chamberlain, McManus, Riley, et al., 2014). This suggests that the relation between perceptual accuracy and drawing ability is not only determined by shape constancy mechanisms, but that reduced susceptibility to angular illusions in general could explain enhanced drawing ability. However, Chamberlain and Wagemans (2015) recently found no correlation between performance on four different contextual illusion tasks (the Ebinghaus, Muller-Lyer, Rod-Frame and Ponzo Illusions) and drawing or artistic ability. Similarly, Schlegel et al. (2015) found no change in susceptibility to the Muller-Lyer illusion after three months of training in observational drawing and painting.

Evidence for a connection between strength of visual illusions and drawing errors is inconclusive. This may be due to task differences between the various studies. A determining factor upon whether the aforementioned studies produced positive findings seems to be the degree of stimulus overlap between the perceptual task and the drawing task. When the drawing and perceptual tasks match precisely (as in Ostrofsky et al., 2015 and Mitchell et al., 2005) reliable relationships between illusion strength and drawing accuracy are found. This could be due to the relationship between canonical representations of objects and the subsequent drawing of them: perceptual distortions for drawn objects follow the distortion of the canonical representation of that object. The degree of distortion of representations may not be consistent across stimuli within participants. In support of this, there is little correlation in the magnitude 
Errors in drawing

of different visual illusions within participants, suggesting that there is not one common mechanism that accounts for inter-individual differences in illusion strength (Grzeckowski et al, 2015). Overall, these data suggest that there is a domain-specific component to perceptual expertise in drawing as well as an intimate link between internal representations of objects and how they are drawn. Task instructions may also impact upon the results of perceptual constancy studies. If participants are told to match the appearance of the stimulus, they may be perfectly able to reproduce their phenomenological representation (i.e. producing the illusory effect). On the other hand, if they are asked to accurately reproduce the distal stimulus, they may perform the task in a different way. The degree to which the observer taps into either of these abilities (perception vs. judgement) is highly dependent on the way in which the task is formulated and described to the participant.

In summary, there is inconclusive evidence for the relationship between perceptual constancy mechanisms, illusory perception and drawing skill. At first glance this appears to refute the innocent eye hypothesis, as artists appear to be unable to overcome fundamental perceptual biases in perception. Indeed, if the innocent eye is construed as a purely perceptual mechanism, the evidence for it is weak. However, the innocent eye can be seen in another light. It can be suggested that the innocent eye is a cognitive mechanism that enables the artist to overcome delusions about categorical and canonical object structure by directing attention to non-semantic object features. In this instance, the innocent eye functions not to train the artists' eye to see more veridically, but to think more veridically. This leads into the role of delusions in drawing, which will now be discussed.

Delusions. In order to make clearer the role of delusions in drawing, it is useful to consider both the positive and negative impacts of knowledge on drawing ability. On the one hand, it has been suggested that explicit knowledge about a subject can have a negative impact on drawing, as it dissuades the artist from drawing what she actually sees rather than what she knows about an object or scene. This is the concept upon which many 'learn to draw' books are based and dates back to Bartlett's (1932) schema theory, in which the faithful representation of a visual object is replaced by a category, linguistic label or 
Errors in drawing

concept. On the other hand, certain forms of top-down knowledge can aid drawing. This was most convincingly argued for by the art theorist Ernst Gombrich (1960), who suggested that instead of accessing an innocent eye, artists compare stored representational schemas to the target object or scene. Gombrich (1960) stated that the artist's challenge lies in, 'conjuring up a convincing image despite the fact that not one individual shade corresponds to what we call 'reality' (p. 49) and therefore the artist must access stored representational structures in order to create an accurate depiction. The evidence on delusions of vision that follows is split into negative categorical schemas, which distort the drawn image by replacing perceptual content with labels or canonical percepts, and positive pictorial schemas, which help the artist to segment the visual scene in systematic ways that aid depiction.

Negative categorical schemas. The negative effect of knowledge on drawing behaviour has been followed up in a series of studies in both artistic and non-artistic adults. An early study showed that labelling ambiguous line drawings affected the way in which they were subsequently drawn, toward a prototypical conception of the labelled object (Carmichael, Hogan, \& Walter, 1932). It has been found that expert artists render novel and familiar items similarly, whereas non-artists show large differences in approach between the two stimulus types (Glazek \& Weisberg, 2010), although this result is confounded by the fact that the three-dimensionality of the groups of items also differed. This suggests that the development of artistic expertise involves an ability to see familiar object and scenes as if they were unfamiliar, in order to reduce the influence of biasing categorical schemas. In support of this contention, Carson, Millard, Quehl and Danckert (2014) found that the orientation of negative space (the space between objects or elements of the visual scene) is drawn more accurately than regions of (identifiable) positive space, while the proportionality of positive space is drawn more accurately than negative space (Figure 5). The effect of familiarity on drawing errors may be due to the fact that familiar objects and their relations are coded categorically when being rendered. Rosielle and Hite (2009) provided evidence for this when they demonstrated that the size relations between simple shapes were exaggerated when participants were asked to draw the two shapes: a phenomenon known as the caricature effect. 


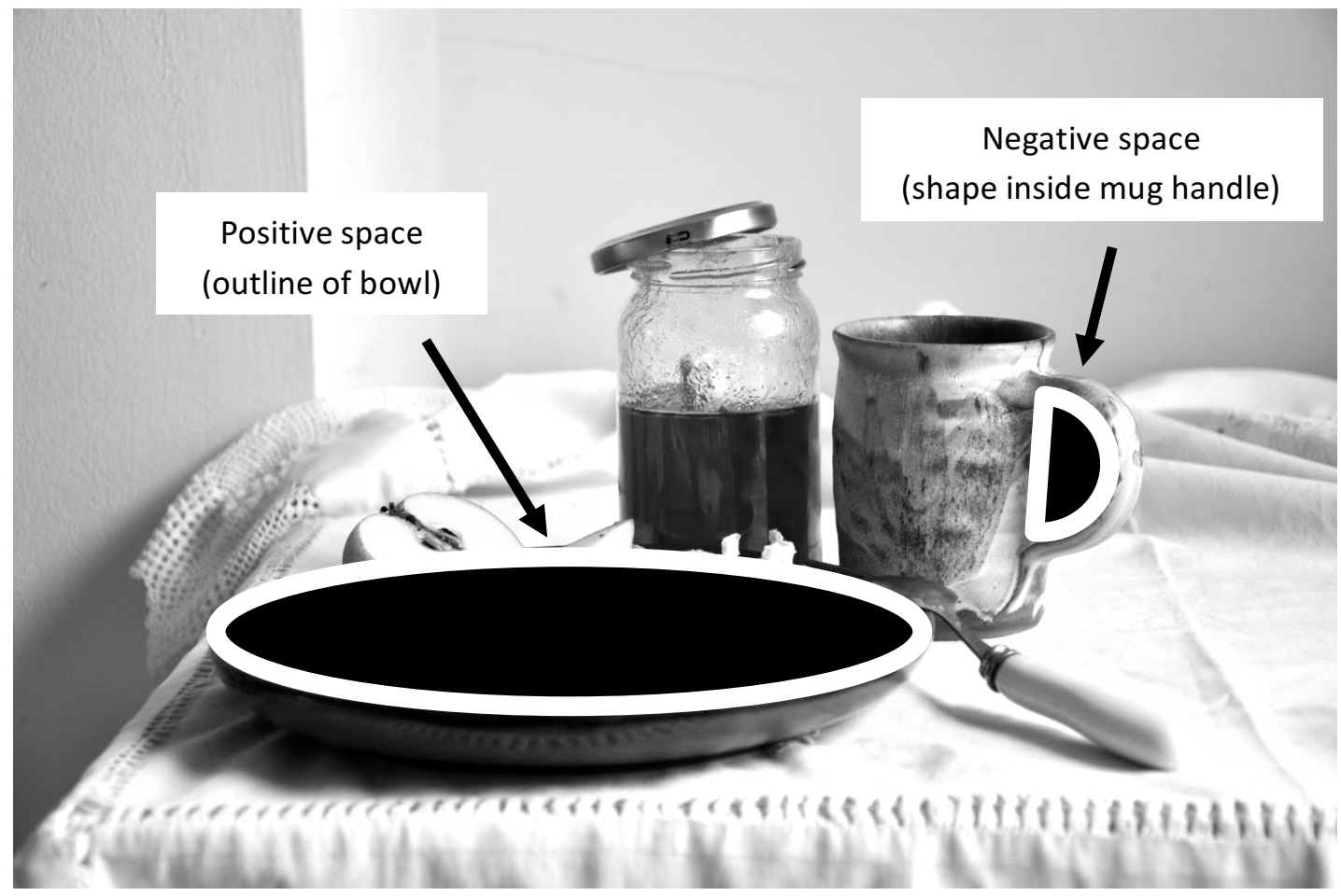

Figure 5. Example of positive and negatives spaces in a typical still life scene.

It is still unclear whether the impact of familiarity of stimuli on drawing results from declarative knowledge about object properties or a canonical visual representation of the to-be-drawn object. Matthews and Adams (2008) argue that artists' internal visual representations are responsible for inaccuracy in drawing. They asked participants to draw a canonical representation of a cylinder before being asked to draw one from real life. The authors found that there was a positive relation between the spatial relations in participants' canonical depictions and the spatial relations in their observational drawings. This effect has also been shown to be true of participants' internal representations of human faces (Ostrofsky et al., 2015), whereby the errors in spatial relations between facial features were correlated between faces drawn from memory and faces drawn from observation. Another wellestablished finding is that of the consistency of inaccurate drawing of facial proportions driven by inaccurate conceptual knowledge about the structure of a human face (Ostrofsky, Cohen, \& Kozbelt, 2014). For example, non-artists frequently draw the eyes of a face too far up the head (Ostrofsky et al., 2014). In a series of experiments, Carbon and Wirth (2014) explored this phenomenon, and concluded 
Errors in drawing

that the eyes were drawn too high as the face was conceived as a flat box shape, leading to an underestimation of the size of the forehead.

A common piece of advice given in instructional drawing texts is that in order to reduce familiarity with the subject and exposure to biases, the novice artist is encouraged to draw from an inverted image to improve drawing accuracy. This exercise makes an appearance in Betty Edwards' popular book 'Drawing on the Right Side of the Brain' (1989) in which she conjectured that switching into 'R-Mode' (engagement with the right brain and its putative holistic perceptual processes) helps novices to master representational drawing. However, two studies which have investigated this phenomenon have found either no impact of inverting an image on drawing accuracy (Cohen \& Earls, 2010), or a small positive effect when observers with artistic expertise were asked to judge the drawings (Kozbelt, Seidel, ElBassiouny, Mark, \& Owen, 2010).

Positive pictorial schemas. Gombrich (1960) argued that cognition has an intrinsic role in perception in the context of art-making. Instead of trying to access some lower-level percept, artists use pictorial schemas (stored spatial and cognitive representations) that enable them to render an object or scene in a particular medium. Gombrich's thesis has been followed up in more recent theoretical accounts, such as that of Tchalenko (2009) and Kozbelt and Seeley (2007), in which the deployment of visual attention to particular aspects if the to-be-drawn object, driven by internal pictorial schemas, is a key feature of the drawing process. Such mechanisms can be conceived to align with delusions, as they represent the reorienting of visual attention through explicit knowledge, perceptual experience or a combination of the two. However, the categorisation of deployment of attention as a delusion is somewhat controversial, and open to debate (see Firestone \& Scholl, in press). Under an attentional interpretation, non-artists fail to produce accurate renderings because they are unable to deploy visual attention in ways that are conducive to accurate depiction. These attentional modes will now be explored.

Local processing. There are a series of studies, motivated by research in the field of autism and Savantism, which suggest that certain attentional strategies may lead to more accurate drawing. In 
Errors in drawing

particular, a robust correlation between drawing accuracy and the ability to focus on local detail in a distracting global context has been found (Chamberlain, McManus, Riley, Rankin, \& Brunswick, 2013; Chamberlain \& Wagemans, 2015; Drake \& Winner, 2011; Drake, 2013; Pring, Ryder, Crane, \& Hermelin, 2010). These studies found that an enhanced ability to segment patterns in the block design task and disembed a target shape from a more complex figure in the embedded figures task (EFT) positively correlate with drawing ability (Figure 6). In addition to enhanced local processing, it has been found that reduced holistic processing of faces (Zhou, Cheng, Zhang, \& Wong, 2012) and an enhanced ability to inhibit global responses in a Navon task (Chamberlain et al., 2013) also predict drawing ability and experience. These findings suggest that artists' visual attention is particularly attuned to inhibiting biasing, reflexive influences on visual perception. This supports the proposal that drawing errors are overcome by inhibiting negative categorical schemas and activating positive pictorial schemas that direct visual attention towards features necessary for accurate depiction.

Global processing. The ability of artists to tune their attention toward coherent global properties of stimuli has also been the focus of empirical research. Kozbelt (2001) found that artist outperformed nonartists on tasks of Gestalt completion and identification of out-of-focus pictures, while Chamberlain and Wagemans (2015) extended this enhancement to coherent motion processing. A recent study by Perdreau and Cavanagh (2013) demonstrated that individuals who can draw more accurately are better at integrating local elements of a stimulus across eye movements. However, the degree to which individuals extract Gestalt properties of visual objects does not appear to explain the link between the perception abilities and drawing. Ostrofsky, Kozbelt and Kurylo (2013) tested artists and non-artists on various measures of perceptual grouping on the basis of luminance, colour and orientation, finding no difference in performance between the two groups. Similarly, Perdreau and Cavanagh (2011) found no difference in amodal completion between artists and non-artists. This may be due to the fact that extraction of Gestalt properties is sufficiently low-level (like visual illusions and perceptual constancies) to be impervious to top-down attentional control. 
Errors in drawing

Attentional flexibility. The results of a recent study suggest that those with advanced drawing skill can flexibly switch between task-relevant perceptual levels of hierarchical stimuli in a Navon shape task (Chamberlain \& Wagemans, 2015). This suggests that rather than possessing some kind of attentional bias, artists are able to flexibly attend to pertinent stimulus attributes. Artists' flexibility of visual attention is currently being investigated using bistable figures like the Necker cube (Figure 6) and structure-from-motion (SFM) stimuli. Preliminary data suggest that artists are better than non-artists at voluntarily switching between bistable percepts but are no better at voluntarily holding a particular representation in mind (Chamberlain \& Wagemans, 2016). These findings represent a promising avenue for future research in the field by shifting the focus of research from biases in attention to a more general attentional flexibility toward visual stimuli.
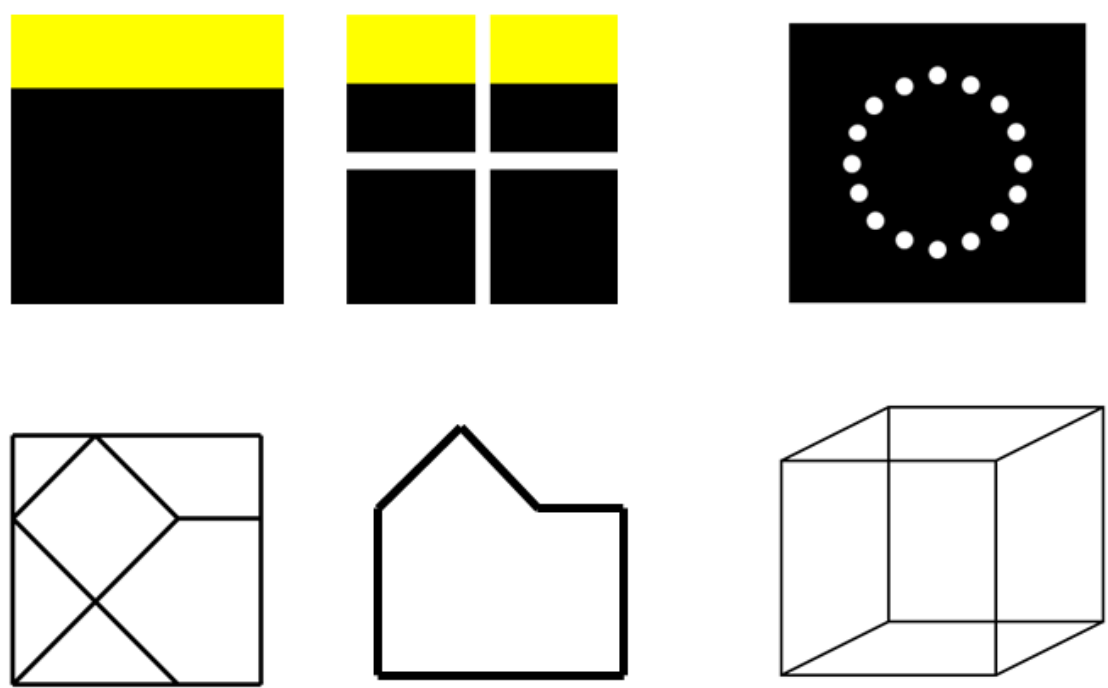

Figure 6. Tasks that assess local visual processing and perceptual flexibility (clockwise from top left): Stimulus patterns from the Block design task, a Navon hierarchical figure, the Necker bistable cube and an example trial from the EFT.

Taken as a whole, these findings suggest that delusions in vision are a large source of drawing error. There is evidence that both canonical representations in memory and categorical knowledge about object and scene properties drive drawing errors, and that manipulating the familiarity of the stimulus 
Errors in drawing

does not alleviate this problem, as inverting an image does not drastically improve drawing accuracy. Instead, it would appear that a wealth of perceptual experience and appropriate knowledge about the structure of the visual world lead to the generation of more convincing representations, in line with Gombrich (1960). Attentional findings lead to the conclusion that perceptual experience and knowledge turn visual attention to aspects of the stimulus that ameliorate the impact of bias from both bottom-up and top-down sources. In support of this, there is growing evidence that flexibility of visual attention is the main driver of top-down effects on vision for drawing. The appropriate allocation of visual attention in line with positive pictorial schemas is likely to be controlled by the representational decisions of the artist, which will be discussed in the subsequent section.

\section{Representational decisions}

The role of representational decisions was downplayed in Cohen and Bennett's (1997) study. However, given the growing evidence for top-down control over visual processing under the schema theory of Gombrich (1960), drawing researchers have revisited this issue in recent years. The critical value of making the right representational decisions is illustrated in the series of prints of a bull by Pablo Picasso (Figure 7). In this series of lithographs, Picasso gradually extracts essential visual features of the bull figure. But even in the first (arguably most pictorially accurate) print Picasso made subtle representational decisions in order to render the likeness of the bull. Furthermore, with each subsequent abstraction a key visual property of the image, self-similarity, does not change, while other image statistics of the image do (Redies, Brachmann, \& Hayn-Leichsenring, 2015). This suggests that an artist must select visual features that are somehow integral to the underlying structure of the object or scene to produce a successful rendering. Loss of critical information will result in a poor drawing. 

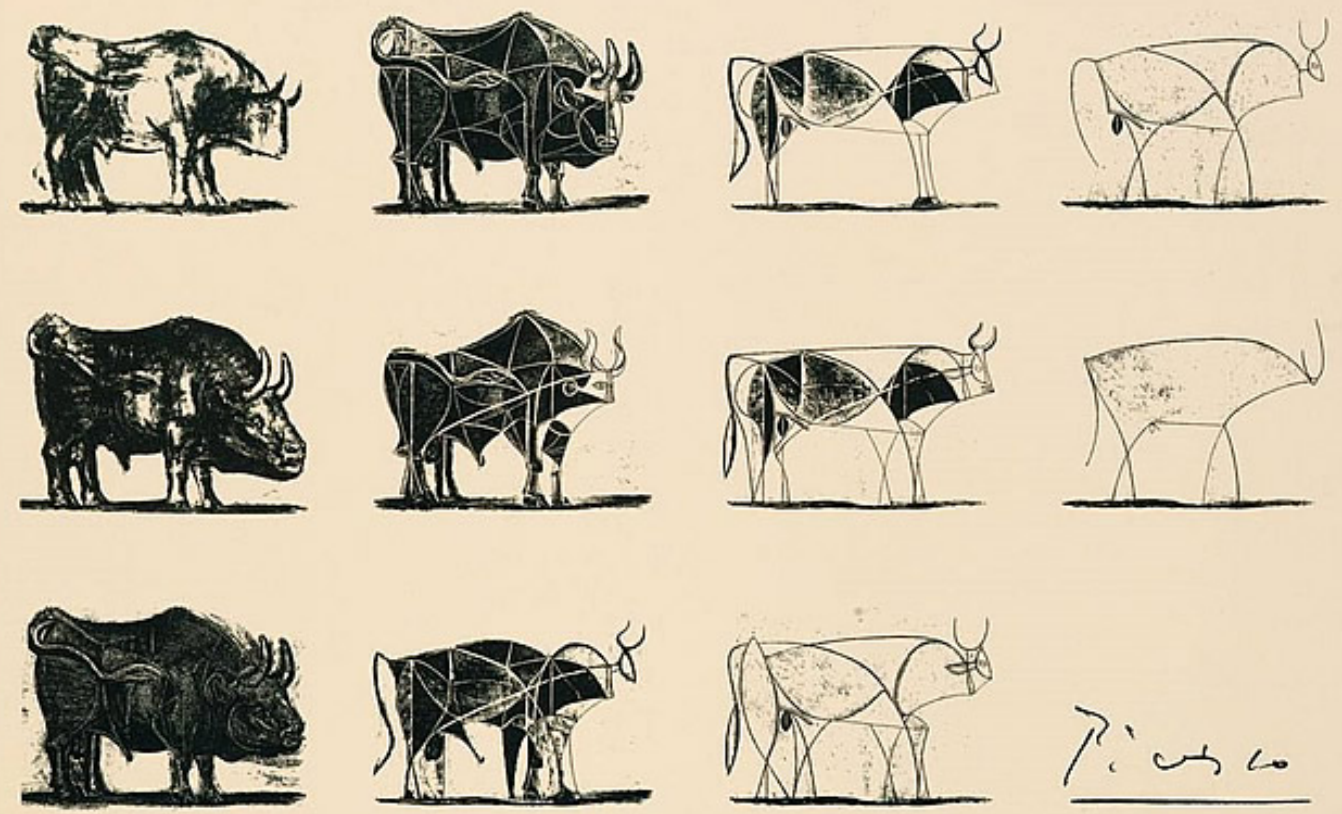

Figure 7. A series of lithographic prints of a bull by Pablo Picasso (Bull, 1945).

Representational decisions are closely connected to visual attention, as attention to appropriate aspects of the to-be-drawn stimulus will drive those features that are represented and strategies for depiction will drive visual attention toward certain features. In an elegant paradigm, Kozbelt et al. (2010) and Ostrofsky et al. (2012) explored how artists select essential visual features for observational drawing. In this minimal line drawing task participants were given a limited number of strips of tape with which to render a photographic image. Ostrofsky et al (2012) reported that artistic subgroups were better than non-artists at producing minimal line drawings that convincingly rendered the photographic subject (Figure 8). The authors proposed that this was because the artists' renderings included more features necessary for object recognition, such as junctions and occlusion barriers. As well as group differences (Kozbelt et al., 2010), these studies also showed that minimal line tracing performance was correlated with observational drawing skill (Ostrofsky et al., 2012), suggesting that the selection of appropriate visual features for rendering is in fact a key feature of drawing ability. An as yet untested hypothesis would be that artists direct their visual attention to these kinds of critical identification features more when drawing in 
Errors in drawing

comparison to non-artists. This would make explicit the link between representational decisions made by the artist and the direction of visual attention toward the image and the evolving drawing.

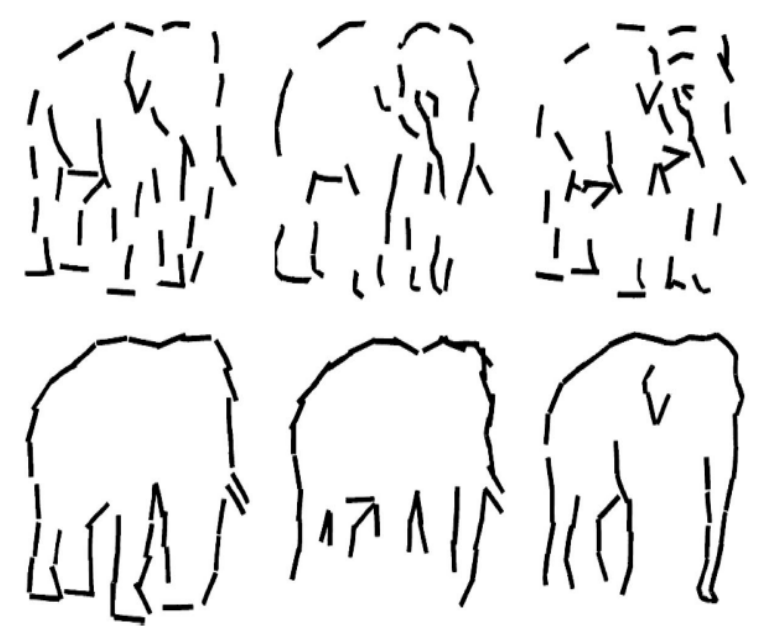

Figure 8. Minimal line drawing task used in Ostrofsky et al. (2012). The minimal line drawings made by artists are displayed in top row and those made by non-artists are below.

In order to make sound representational decisions for drawing, the subject needs to be broken down into appropriate features or chunks. Thus, segmentation of the object or scene is also a key aspect of drawing performance. Tchalenko (2009) measured the eye and hand movements of expert and non-artists while they drew. These data revealed that artists segmented a complex line segment into a series of simple lines, and reproduced these simple component parts using a particular eye-hand strategy. Whilst experts appear to segment the image systematically, non-artists enact a mixture of arbitrary segmentation and no segmentation of complex lines (Tchalenko, 2009). Miall et al. (2014) showed that the gaze ratio (time spent looking at the object/ time spent looking at the drawing) changed in relation to how well-defined the visual stimulus was (a line, a silhouette and spatially filtered photographs); the gaze ratio was lowest when participants were copying a line drawing of abstract and meaningful stimuli. This demonstrates the bidirectional link between visual attention and representational decisions made in reference to the visual stimulus, a link that is harnessed by expert artists to refine the drawing process. 
Errors in drawing

In summary, representational decisions are an important facet of the development of drawing expertise, contrary to Cohen and Bennett's (1997) original assertion. Artists must know which parts of the visual image to select and attend to, and this selection process is critical for later identification of the drawn image. This selection process may be driven by features for object identification, but this conjecture warrants further examination. This is complicated by the fact that the essential features for object segmentation and identification are still under some debate, but internal object features such as the the medial axis (Firestone \& Scholl, 2014) or external contour-based features such as minima of curvature (De Winter \& Wagemans, 2006) may be promising avenues of exploration. It would also be useful to know which representational decisions are driven by lower-level visual qualities of the stimulus (like figure-ground segmentation), and which are driven by top-down considerations based on the identity of the object or scene to be drawn (based on knowledge of semantically essential object properties). Finally, a more systematic study of how artists segment complex lines and 3D forms is also necessary in order to characterise segmentation strategies for drawing across individuals. To date researchers have only used tasks that required participants to copy a line drawing (Tchalenko, 2009). It would be worthwhile to investigate how this segmentation plays out when individuals draw an object or scene from a complete three-dimensional representation.

\section{Motor Skills}

Cohen and Bennett (1997) concluded that fine motor skills do not play a significant role in individual differences in drawing by demonstrating that participants can adequately trace a drawing with little error, in striking contrast to the large errors made during freehand copying. Similarly, Edwards (1989) stated that, 'contrary to popular opinion, manual skill is not a primary factor in drawing. If your handwriting is readable, or if you can print legibly, you have ample dexterity to draw well' (p. 3). A recent study by McManus et al. (2014) tested art students and non-art students on a range of motor control and drawing tasks. No relationship was found between performance in the motor tasks and drawing skill. Fine motor skill therefore is not likely to be implicated in individual differences in drawing ability. However, hand 
Errors in drawing

and eye movements are known to have strong bidirectional influences and therefore it is highly likely that motor movements do play a role, but only when considered in their interplay with eye movements (Ballard et al., 1992; Gowen \& Miall, 2006). The complex relation between the hand and the eye can only be addressed when researchers take on the substantial challenge of studying the drawing process as well as its output.

Glazek (2012) measured both hand and eye movements in a naturalistic drawing task to assess whether motor output showed characteristics of expertise as well as perceptual output. Experts' motor output to visual input ratios were larger. Motor output to visual input ratios also correlated with sketching accuracy. This implies that expert artists are able to produce more motor output per unit of visually encoded material when drawing. Tchalenko (Tchalenko, Nam, Ladanga, \& Miall, 2014; Tchalenko, 2007, 2009) has explored the coordination of hand and eye movements during drawing, finding that eye movements tend to represent either close pursuit or gaze locking. In the former coordinated movement the hand takes the lead, whereas in the latter the eye does so. In a recently expounded theory, the Gaze Shift Strategy, Tchalenko et al. (2014) describe an iterative loop in which a motor programme is formulated whilst looking at the subject, that can be deployed as soon as the artist moves their attention back from the paper, with the eye helping to spatially position the beginning of the line on the paper, and monitor the resulting hand movement. Large parts of the time spent drawing are spent 'blind drawing' during which time the artist does not look at his drawing hand. In a functional neuroimaging study, Miall, Gowen and Tchalenko (2009) found that the act of drawing blind remains consistent with visually guided action, despite lack of direct visual input.

It can be concluded that while fine motor skills are unlikely to play a key role in the determination of drawing abilities, the intimate connection between hand and eye is critical for the drawing process. Periods spent blind drawing suggest that complex visuomotor planning is at the heart of drawing, as was put forward by Kozbelt and Seeley (2007) in their visuomotor model for artists' perceptual advantages, which was supported by the findings of a recent neuroimaging study 
Errors in drawing

(Chamberlain, McManus, Brunswick, et al., 2014). Kozbelt and Seeley (2007) postulated a looped model encompassing brain regions for procedural knowledge and various stages of the visual hierarchy, including visual memory. Kozbelt (2001) presented evidence for this when it was found that there was left-over variance discriminating artists from non-artists after perceptual differences between the two had been partialled out, suggesting differences in visuo-motor integration between the two groups.

\section{Visual Memory}

Somewhat surprisingly, the role of visual memory was not addressed in Cohen and Bennett's (1997) original paper, although it has been thought for a long period of time that the drawing process involves some translation from perception to memory to motor action. As Kimon Nicolaides (1941) notes in his instructional book on representational drawing,

"With the exception of the contour study, there is no drawing that is not a memory drawing because, no matter how slight the interval is from the time you look at the model until you look at your drawing or painting, you are memorizing what you have just seen". (p. 40)

The obvious exception to this is the kind of blind drawing described in Tchalenko's Gaze Shift strategy (2014) which takes up a substantial proportion of the time the artist spends drawing. In a causal study, Cohen (2005) found that increasing the rate of gaze shifting between drawing and to-be-drawn object increased drawing accuracy, suggesting that reduced reliance on visual memory leads to more accurate drawing. However, in support of the intuition that visual memory does play a role in some stages of the drawing process, studies have shown that individuals with better visual memory produce more accurate drawings. McManus et al. (2010) and Chamberlain, McManus, Brunswick, Rankin and Riley (2015) showed that performance on the immediate and delayed recall conditions of the Rey Osterrieth Complex Figure Test correlated with drawing accuracy of a block construction and a hand, and that this could not be accounted for by differences in copying the figure (Figure 9). In their study on shape constancy, Cohen 
Errors in drawing

and Jones (2008) also found that delayed recognition of faces and facial features was correlated with drawing accuracy.

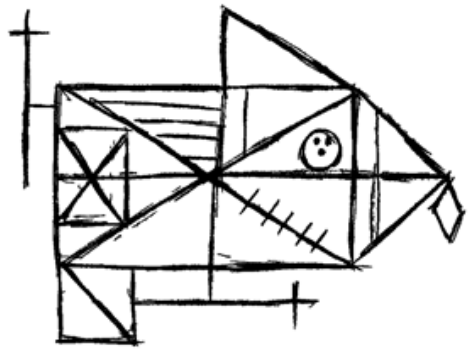

Good copy of Rey-Osterrieth (Score=35)

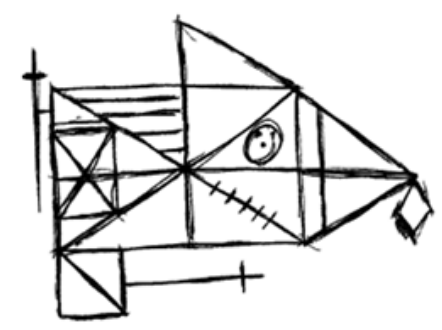

Good recall of Rey-Osterrieth (Score $=33$ )

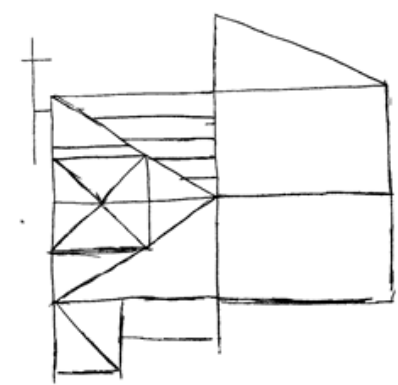

Poor copy of Rey-Osterrieth (Score=16.5)

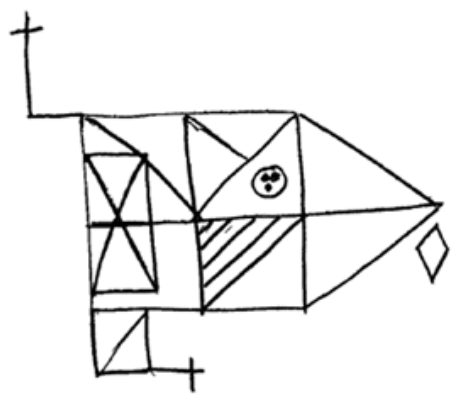

Poor recall of Rey-Osterrieth (Score=15.5)

Figure 9. Examples of drawings of the Rey Osterrieth Complex Figure from Chamberlain (2013).

There is also evidence to suggest that enhanced visual encoding is related to drawing accuracy. Glazek and Weisberg (2010) found that the amount of time encoding familiar and novel graphic stimuli differed between artists and non-artists, with the artist subgroup encoding more quickly than the nonartists. Perdreau and Cavanagh (2014) recently found that drawing accuracy was predicted by encoding of objects both in central and peripheral vision, and that this superior encoding can be used by artists to support better visual integration ability (Perdreau \& Cavanagh, 2013). In another study, Perdreau and Cavanagh (2015) found that skilled draftsmen were more likely to notice masked changes to their drawings or the to-be-drawn object, suggesting a richer or more durable stored representation of the 
Errors in drawing

subject and the drawing. However, no relationship was found between performance on a change detection paradigm that did not involve drawing and representational drawing skill (Perdreau \& Cavanagh, 2015), suggesting that enhanced memory is to some degree domain-specific (i.e. it can only be utilised in the context of encoding for drawing). Cohen and Jones (2008), McManus et al. (2010), and Chamberlain et al. (2015) found that both encoding and retention independently predicted drawing ability, suggesting that both qualities of visual memory aid the draftsman. In conclusion, enhanced encoding and retention is likely to be involved with drawing, but there is also evidence to suggest that strategies that decrease reliance on memorial abilities are a fundamental pathway to gaining drawing expertise. Furthermore, enhanced memory in relation to drawing appears to only be present in the context of the drawing process, and shows little generalisation to memory tasks that do not involve drawing.

\section{Discussion}

Since Cohen and Bennett's (1997) paper on the generation of errors in observational drawing, a number of studies have investigated the relationship between drawing skill and various perceptual, memorial and motor abilities. While at first glance some findings appear contradictory or unclear, patterns in the data can be seen, particularly in regard to the topic of misperception for which there now exists a substantial amount of data (Figure 10). What is most striking about the perceptual findings is the lack of conclusive data on the relationship between lower-level perceptual abilities such as perceptual constancies and grouping, and drawing skill. This finding is supported by recent functional and structural brain imaging studies that show that artistic training does not result in changes in lower regions of the visual hierarchy but in regions that support visuo-motor integration (Chamberlain et al., 2014; Schlegel et al., 2015). The phenomenal experiences of artists' perceptual constancies and gestalts appear to remain similar to those of non-artists, and task-dependent changes in the allocation of visual attention appear to be more critical to characterising artistic perception.

Illusion or delusion? There is reliable evidence to suggest that delusions are responsible for both success and failure in drawing. By contrast, individual differences in perceptual constancies, visual 
Errors in drawing

illusions and Gestalt perception do not strongly correlate with drawing skill, implying learnt or innate differences in low-level perceptual representations play little role. However, it should be emphasised that the conceptual boundary between perception and cognition can often by blurred (Figure 1). For example, the influence of canonical representations are presented in this review as delusions, but could be argued to be failures of stored visual perception. Similarly, the allocation of visual attention to different regions or features of the visual scene could be seen as a modification of perception not just conception, working within the visual module rather than outside it. In this case, it is helpful to make more subtle distinctions within illusory and delusory percepts in order to tease out the most likely predictors of drawing error. This should be an active area of future research.

Individual differences in visual attention reliably predict drawing ability. Recent studies revealed that rather than representing a bias toward particular aspects of images, enhanced performance in local and global processing tasks represents flexibility toward visual stimuli that may enable the artist to attend to task-relevant visual features (Chamberlain \& Wagemans, 2015; Chamberlain \& Wagemans, 2016). Kozbelt et al (2010) and Ostrofsky et al (2012) concluded that experienced artists flexibly implement strategies that address perceptual ambiguities, recasting artists' advantages as advantages of attention rather than perception. A recent theoretical account echoes these conclusions by proposing that artists switch between proximal and distal modes of perception while creating works of art (Lou, 2015). The view-independent distal mode of perception can be equated to Gombrich's representational schemas as they represent how things look out in the world, whilst the view-dependent proximal mode is more akin to Ruskin's innocent eye, as they represent how things look to the observer. Lou (2015) argued that artists can transfer efficiently between these two modes depending on their depictive goals. These findings and theoretical perspectives suggest that the tension between schema-based and innocent eye-based perspectives may be resolved by recourse to a flexible visual system which focuses on harnessing or dispelling positive and negative representational schemas. A dual-mode enhancement may also explain why findings in the perceptual constancy literature have been inconsistent, as participants may choose to 
Errors in drawing

attend to the biasing context or not, depending on how they interpret the task instructions. Whilst evidence grows in support of this perspective, it is unclear how flexibility of visual attention develops. Does it arise through declarative knowledge about the visual environment (e.g. the eyes are halfway up the head), through tools used to modify visual experience (e.g. closing one eye to eliminate binocular depth cues) or merely through sustained interaction with particular visual stimuli? This is an area with rich potential for investigation which will require well-controlled longitudinal designs to investigate the role of these influences on visual attention as they take shape over time. 
Errors in drawing
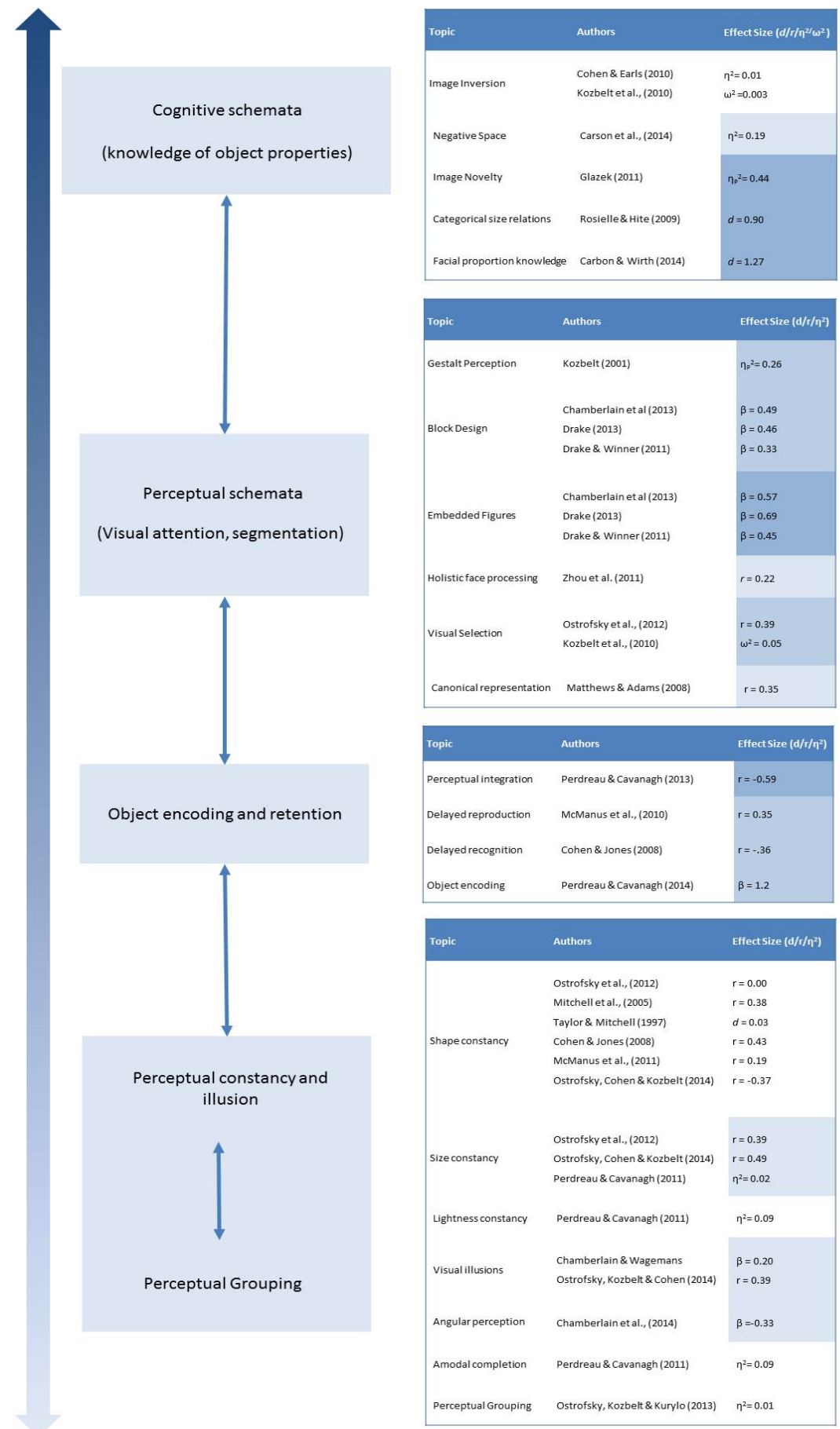

(10)

Figure 10. The strength of effects of misperception associated with drawing. Where studies involve multiple experiments and analyses, effect sizes have drawn from the most representative finding from each paper. 
Errors in drawing

The drawing process. The drawing process is worthy of far more examination. Until now, few researchers have made notable efforts to break down the drawing process to understand the complex interactions between cognition, perception and action. Data from Tchalenko's studies $(2007 ; 2009 ; 2014)$ suggest a reduction in reliance on visual memory systems in drawing, characterised by the Gaze-Shift strategy which has been shown to have causal effects on drawing ability (Cohen, 2005), while a reliable relation between object encoding, retention and drawing skill has been found (Chamberlain et al., 2015; Perdreau \& Cavanagh, 2015). Whilst artists may use the gaze shift strategy to reduce the likelihood of error due to incorrect canonical representations (Matthews \& Adams, 2008), it is logical that they also work on improving their memory system for those instances in which blind drawing is not possible. In particular, the use of visual memory may be particularly important when comparing the drawing with its subject and when placing spatial landmarks on the page. This is supported by Perdreau and Cavanagh's (2015) study regarding change detection during the drawing process. A facet highlighted by this study is the domain-specificity of these memory effects. All visual memory studies included here show an enhancement of visual memory correlated with drawing skill only in tasks that require drawing. Aside from the null finding in a change detection task in Perdreau and Cavanagh's study (2015), no evidence of null findings with regard to non-drawing visual memory tasks could be found, most likely due to a positive publication bias. Unpublished work found the same effect, in which visual memory for symbols and angles and proportions between pairs of lines showed no systematic correlation with drawing skill (Chamberlain, 2013). However, absence of evidence is not evidence of absence, and continued work assessing the relationship between visual memory ability and drawing is necessary, again by harnessing the process as well as the product of drawing.

\section{Conclusion}

The subtlety and complexity of the findings presented here is reflective of the subtlety and complexity of the drawing process itself. The data speak to both the art historical approaches of Ruskin and Gombrich, who placed emphasis on bias-free perception and schematic perception of stimuli for representation, 
Errors in drawing

respectively. Considered together, the findings presented here emphasise the impact of prior knowledge and representation on the interpretation of incoming visual information. There does not appear to be an equivalent of the artistic 'innocent eye' as Ruskin speculated, where all visual input is taken at face value without further recourse to knowledge structures and perceptual schemata. However, this conclusion is to some extent dependent on the way in which the concept of the innocent eye is interpreted. If the innocent eye is construed as a mechanism by which visual attention is trained away from negative categorical schemas so that the input to the perceptual module is changed, then there exists clear evidence for its presence. If on the other hand it is conceptualised as a fundamental change of perceptual content within the perceptual module itself, the data are inconclusive. Findings in this review cohere to support the suppression of negative categorical schemas and the activation of positive pictorial schemas. To a large extent it can be proposed that the amelioration of negative biases and the strengthening of positive schemas function independently, such that the training artist must use tools and techniques for the engagement of both. For example, the use of negative space or squinting to eliminate local detail can be seen as tools for suppressing negative categorical schemas, whilst plotting the pivotal points on a human body and using anatomical knowledge of musculature can be seen as positive pictorial schemas. The artist must harness both channels and be able to flexibly switch between them at the correct moment in order to create an accurate representation of an object or scene.

What implications does the development of flexible attentional mechanism for drawing have for artistic functioning more generally? It can be speculated that attentional modulators of visual perception, particularly those that enable the artist to attend to different visual features and switch between multiple interpretations of the same visual input, could facilitate higher forms of artistic production and appreciation. However, there is no data to speak of yet to evaluate this hypothesis directly. Research in the field of aesthetics suggests that aesthetic appreciation is driven by a constant reinterpretation of ambiguous stimuli (Muth, Hesslinger, \& Carbon, 2015). While speculative, it can be hypothesised that artists are better able to engage with artworks in this way through the development of flexible modes of 
Errors in drawing

seeing. If this is the case, one could foresee a link between technical artistic skill, artistic appreciation and creative output. Technical artistic skill under this framework engenders a flexible way of looking at the visual world, which translates into the ability to see multiple interpretations in the work of others (leading to higher aesthetic appreciation) and multiple meanings in incoming sensory and conceptual information. It follows then that observational drawing may be a window into creative thinking. 
Errors in drawing

References

Baldwin, J, Burleigh, A. \& Pepperell, R. (2014). Comparing artistic and geometrical perspective depictions of space in the visual field. i-Perception, 5, 536-547.

Ballard, D. H., Hayhoe, M. M., Li, F., Whitehead, S. D., Frisby, J. P., Taylor, J. G., \& Fisher, R. B. (1992). Hand-eye coordination during sequential tasks [and discussion]. Philosophical Transactions of the Royal Society B: Biological Sciences, 337(1281), 331-339.

Bartlett, F. C. (1932). Remembering: a study in experimental and social psychology. Cambridge, UK: Cambridge University Press.

Bomford, D. (1990). Impressionism. London: National Gallery.

Carbon, C.-C., \& Wirth, B. E. (2014). Neanderthal paintings? Production of prototypical human (Homo sapiens) faces shows systematic distortions. Perception, 43(1), 99-102. http://doi.org/10.1068/p7604

Carmichael, L., Hogan, H. P., \& Walter, A. A. (1932). An experimental study of the effect of language on the reproduction of visually perceived form. Journal of Experimental Psychology, 15(1), 73.

Carson, L. C., \& Allard, F. (2013). Angle-drawing accuracy as an objective performance-based measure of drawing expertise. Psychology of Aesthetics, Creativity, and the Arts, 7(2), 119-129. http://doi.org/10.1037/a0030587

Carson, L., Millard, M., Quehl, N., \& Danckert, J. (2014). Polygon-Based Drawing Accuracy Analysis and Positive/Negative Space. Art \& Perception, 2(1-2), 213-236. http://doi.org/10.1163/22134913-00002021

Cavanagh, P. (2005). The artist as neuroscientist. Nature, 434 (7031), 301-307.

Chamberlain, R. (2013). Drawing conclusions: an exploration of the cognitive and neuroscientific foundations of representational drawing (Unpublished $\mathrm{PhD}$ thesis). University College London, London, UK.

Chamberlain, R., McManus, C., Brunswick, N., Rankin, Q., \& Riley, H. (2015). Scratching the Surface: Practice, Personality, Approaches to Learning, and the Acquisition of High-Level 
Errors in drawing

Representational Drawing Ability. Psychology of Aesthetics, Creativity, and the Arts. http://doi.org/10.1037/aca0000011

Chamberlain, R., McManus, C., Riley, H., Rankin, Q., \& Brunswick, N. (2014). Cain's house task revisited and revived: Extending theory and methodology for quantifying drawing accuracy. Psychology of Aesthetics, Creativity, and the Arts, 8(2), 152-167.

http://doi.org/10.1037/a0035635

Chamberlain, R., McManus, I. C., Brunswick, N., Rankin, Q., Riley, H., \& Kanai, R. (2014). Drawing on the right side of the brain: A voxel-based morphometry analysis of observational drawing. NeuroImage, 96, 167-173. http://doi.org/10.1016/j.neuroimage.2014.03.062

Chamberlain, R., McManus, I. C., Riley, H., Rankin, Q., \& Brunswick, N. (2013). Local processing enhancements associated with superior observational drawing are due to enhanced perceptual functioning, not weak central coherence. The Quarterly Journal of Experimental Psychology, 66(7), 1448-1466. http://doi.org/10.1080/17470218.2012.750678

Chamberlain, R., \& Wagemans, J. (2015). Visual arts training is linked to flexible attention to local and global levels of visual stimuli. Acta Psychologica. 161. 185-197.

Chamberlain, R., \& Wagemans, J. (2016). Visual and cognitive flexibility in artists. Accepted abstract at Vision Science Society Annual Meeting (VSS), St Pete Beach, FL.

Cohen, D. J. (2005). Look little, look often: The influence of gaze frequency on drawing accuracy. Perception \& Psychophysics, 67(6), 997-1009.

Cohen, D. J., \& Bennett, S. (1997). Why can't most people draw what they see? Journal of Experimental Psychology: Human Perception and Performance, 23(3), 609-621.

Cohen, D. J., \& Earls, H. (2010). Inverting an image does not improve drawing accuracy. Psychology of Aesthetics, Creativity, and the Arts, 4(3), 168-172. http://doi.org/10.1037/a0017054

Cohen, D. J., \& Jones, H. E. (2008). How shape constancy relates to drawing accuracy. Psychology of Aesthetics, Creativity, and the Arts, 2(1), 8-19. http://doi.org/10.1037/1931-3896.2.1.8 
Errors in drawing

De Winter, J., \& Wagemans, J. (2006). Segmentation of object outlines into parts: A large-scale integrative study. Cognition, 99(3), 275-325. http://doi.org/10.1016/j.cognition.2005.03.004

Drake, J. E. (2013). Is superior local processing in the visuospatial domain a function of drawing talent rather than autism spectrum disorder? Psychology of Aesthetics, Creativity, and the Arts, 7(2), 203-209. http://doi.org/10.1037/a0030636

Drake, J. E., \& Winner, E. (2011). Realistic Drawing Talent in Typical Adults is Associated with the Same Kind of Local Processing Bias Found in Individuals with ASD. Journal of Autism and Developmental Disorders, 41(9), 1192-1201. http://doi.org/10.1007/s10803-010-1143-3

Edwards, B. (1989). Drawing on the right side of the brain. New York: Putnam.

Firestone, C., \& Scholl, B. J. (2014). "Please tap the shape, anywhere you like": shape skeletons in human vision revealed by an exceedingly simple measure. Psychological Science, 25(2), 377-386.

Firestone, C., \& Scholl, B. J. (in press). Cognition does not affect perception: Evaluating the evidence for 'top-down' effects [target article]. Behavioral and Brain Sciences

Glazek, K. (2012). Visual and motor processing in visual artists: Implications for cognitive and neural mechanisms. Psychology of Aesthetics, Creativity, and the Arts, 6(2), 155-167. http://doi.org/10.1037/a0025184

Glazek, K. J., \& Weisberg, R. W. (2010). Expertise in Visual Art is Associated with Altered Perceptual Strategies Within and Across Domains: Evidence from Eye Tracking. In Proceedings of the 32nd Annual Conference of the Cognitive Science Society (pp. 417-422). Retrieved from http://csjarchive.cogsci.rpi.edu/proceedings/2010/papers/0070/paper0070.pdf

Gombrich, E. H. (1960). Art and Illusion. Princeton, NJ: Princeton University Press.

Gowen, E., \& Miall, R. C. (2006). Eye-hand interactions in tracing and drawing tasks. Human Movement Science, 25(4-5), 568-585. http://doi.org/10.1016/j.humov.2006.06.005

Gregory, R. L. (2003). Delusions. Perception, 32(3), 257-261. http://doi.org/10.1068/p3203ed

Grzeczkowski, L., Clarke, A., Mast, F., \& Herzog, M. (2015). No correlations between the magnitude of visual illusions. Journal of Vision, 15(12), 1132. 
Errors in drawing

Hammad, S., Kennedy, J. M., Juricevic, I., \& Rajani, S. (2008). Angle illusion on a picture's surface. Spatial Vision, 21(3), 451-462.

Jolley, R. P., O’Kelly, R., Barlow, C. M., \& Jarrold, C. (2013). Expressive drawing ability in children with autism. British Journal of Developmental Psychology, 31(1), 143-149. http://doi.org/10.1111/bjdp.12008

Karmiloff-Smith, A. (1990). Constraints on representational change: evidence from children's drawings. Cognition, 34, 57-83.

Kozbelt, A. (2001). Artists as experts in visual cognition. Visual Cognition, 8(6), 705-723. http://doi.org/10.1080/13506280042000090

Kozbelt, A., \& Seeley, W. P. (2007). Integrating art historical, psychological, and neuroscientific explanations of artists' advantages in drawing and perception. Psychology of Aesthetics, Creativity, and the Arts, 1(2), 80-90. http://doi.org/10.1037/1931-3896.1.2.80

Kozbelt, A., Seidel, A., ElBassiouny, A., Mark, Y., \& Owen, D. R. (2010). Visual selection contributes to artists' advantages in realistic drawing. Psychology of Aesthetics, Creativity, and the Arts, 4(2), 93-102. http://doi.org/10.1037/a0017657

Lou, L. (2015). Observational visual depiction involves interplays of proximal and distal modes of seeing. Presented at the Visual Science of Art Conference, Liverpool, UK.

Matthews, W. J., \& Adams, A. (2008). Another reason why adults find it hard to draw accurately. Perception, 37(4), 628-630. http://doi.org/10.1068/p5895

McManus, C., Ying, B. T. Z., Fleming, E., Lee, P., \& Chamberlain, R. (2014). Testing Ruskin: seeing, drawing and remembering complex curves. Presented at the Visual Science of Art Conference, Belgrade, Serbia.

McManus, I. C., Chamberlain, R., Loo, P.-W., Rankin, Q., Riley, H., \& Brunswick, N. (2010). Art students who cannot draw: Exploring the relations between drawing ability, visual memory, accuracy of copying, and dyslexia. Psychology of Aesthetics, Creativity, and the Arts, 4(1), 1830. http://doi.org/10.1037/a0017335 
Errors in drawing

McManus, I. C., Loo, P.-W., Chamberlain, R., Riley, H., \& Brunswick, N. (2011). Does shape constancy relate to drawing ability? Two failures to replicate. Empirical Studies of the Arts, 29(2), 191-208.

Miall, R. C., Gowen, E., \& Tchalenko, J. (2009). Drawing cartoon faces - a functional imaging study of the cognitive neuroscience of drawing. Cortex, 45(3), 394-406. http://doi.org/10.1016/j.cortex.2007.10.013

Miall, R. C., Nam, S.-H., \& Tchalenko, J. (2014). The influence of stimulus format on drawing-a functional imaging study of decision making in portrait drawing. NeuroImage, 102, 608-619. http://doi.org/10.1016/j.neuroimage.2014.08.015

Mitchell, P., Ropar, D., Ackroyd, K., \& Rajendran, G. (2005). How Perception Impacts on Drawings. Journal of Experimental Psychology: Human Perception and Performance, 31(5), 996-1003. http://doi.org/10.1037/0096-1523.31.5.996

Muth, C., Hesslinger, V. M., \& Carbon, C.-C. (2015). The appeal of challenge in the perception of art: How ambiguity, solvability of ambiguity, and the opportunity for insight affect appreciation. Psychology of Aesthetics, Creativity, and the Arts, 9(3), 206-216. http://doi.org/10.1037/a0038814

Nicolaides, K. (1941). The natural way to draw: a working plan for art study. Boston, MA: Houghton Mifflin.

Ostrofsky, J., Cohen, D. J., \& Kozbelt, A. (2014). Objective versus subjective measures of face-drawing accuracy and their relations with perceptual constancies. Psychology of Aesthetics, Creativity, and the Arts, 8(4), 486-497.

Ostrofsky, J., Kozbelt, A., \& Cohen, D. J. (2015). Observational drawing biases are predicted by biases in perception: Empirical support of the misperception hypothesis of drawing accuracy with respect to two angle illusions. The Quarterly Journal of Experimental Psychology, 68(5), 1007-1025. http://doi.org/10.1080/17470218.2014.973889

Ostrofsky, J., Kozbelt, A., \& Kurylo, D. (2013). Perceptual grouping in artists and non-artists: a psychophysical comparison. Empirical Studies of the Arts, 31(2), 131-143. 
Errors in drawing

Ostrofsky, J., Kozbelt, A., \& Seidel, A. (2012). Perceptual constancies and visual selection as predictors of realistic drawing skill. Psychology of Aesthetics, Creativity, and the Arts, 6(2), 124-136. http://doi.org/10.1037/a0026384

Pepperell, R \& Haertel, M. (2014). Do artists use linear perspective to depict visual space? Perception, 43(5), 395-416

Perdreau, F., \& Cavanagh, P. (2011). Do Artists See Their Retinas? Frontiers in Human Neuroscience, 5. http://doi.org/10.3389/fnhum.2011.00171

Perdreau, F., \& Cavanagh, P. (2013). The artist's advantage: Better integration of object information across eye movements. I-Perception, 4(6), 380-395. http://doi.org/10.1068/i0574

Perdreau, F., \& Cavanagh, P. (2014). Drawing skill is related to the efficiency of encoding object structure. I-Perception, 5(2), 101-119. http://doi.org/10.1068/i0635

Perdreau, F., \& Cavanagh, P. (2015). Drawing experts have better visual memory while drawing. Journal of Vision, 15(5), 5. http://doi.org/10.1167/15.5.5

Pring, L., Ryder, N., Crane, L., \& Hermelin, B. (2010). Local and global processing in savant artists with autism. Perception, 39(8), 1094-1103. http://doi.org/10.1068/p6674

Redies, C., Brachmann, A., \& Hayn-Leichsenring, G. U. (2015). Changes of Statistical Properties During the Creation of Graphic Artworks. Art \& Perception, 3(1), 93-116. http://doi.org/10.1163/22134913-00002017

Rosielle, L. J., \& Hite, L. A. (2009). The caricature effect in drawing: Evidence for the use of categorical relations when drawing abstract pictures. Perception, 38(3), 357-375. http://doi.org/10.1068/p5831

Ruskin, J. (1856). The elements of drawing. Mineola, NY: Dover Publications Inc.

Schlegel, A., Alexander, P., Fogelson, S. V., Li, X., Lu, Z., Kohler, P. J., ... Meng, M. (2015). The artist emerges: Visual art learning alters neural structure and function. NeuroImage, 105, 440-451. http://doi.org/10.1016/j.neuroimage.2014.11.014 
Errors in drawing

Shah, A., \& Frith, U. (1993). Why do autistic individuals show superior perforamce on the block design task? Journal of Child Psychology and Psychiatry, 34, 1351-1364.

Taylor, L. M., \& Mitchell, P. (1997). Judgments of apparent shape contaminated by knowledge of reality: Viewing circles obliquely. British Journal of Psychology, 88(4), 653-670.

Tchalenko, J. (2007). Eye movements in drawing simple lines. Perception, 36(8), 1152-1167. http://doi.org/10.1068/p5544

Tchalenko, J. (2009). Segmentation and accuracy in copying and drawing: Experts and beginners. Vision Research, 49(8), 791-800. http://doi.org/10.1016/j.visres.2009.02.012

Tchalenko, J., Nam, S.-H., Ladanga, M., \& Miall, R. C. (2014). The gaze-shift strategy in drawing. Psychology of Aesthetics, Creativity, and the Arts, 8(3), 330-339. http://doi.org/10.1037/a0036132

Thouless, R. H. (1932). Individual differences in phenomenal regression. British Journal of Psychology, $22,216-241$.

Tversky, B. (1990). What does drawing reveal about thinking? In Visual and spatial reasoning in design (pp. 93-101). Sydney, Australia: Key Centre of Design Computing and Cognition.

Witkin, H., Oltman, P., Raskin, E., \& Karp, S. (1971). A manual for the embedd figures test. Consulting Psychologists Press Inc.

Zhou, G., Cheng, Z., Zhang, X., \& Wong, A. C.-N. (2012). Smaller holistic processing of faces associated with face drawing experience. Psychonomic Bulletin \& Review, 19(2), 157-162. http://doi.org/10.3758/s13423-011-0174-x 